\title{
Electrochemical $\mathrm{Cr}(\mathrm{VI})$ Reduction over Terpyridine-Derivatized Ti Sheets
}

\author{
Received August 25, 2020; accepted September 17, 2020
}

\author{
Jae Moon Yia, So Jeong Park ${ }^{\mathrm{a}}$, Choong Kyun Rhee ${ }^{\mathrm{a}}$, and Youngku Sohn ${ }^{\mathrm{a}, \mathrm{b}^{*}}$ \\ aDepartment of Chemistry, Chungnam National University, Daejeon 34134, Republic of Korea \\ ${ }^{b}$ Department of Chemical Engineering and Applied Chemistry, Chungnam National University, Daejeon 34134 , Republic of Korea
}

*Corresponding author E-mail: youngkusohn@cnu.ac.kr

\begin{abstract}
$\mathrm{Cr}(\mathrm{VI})$ reduction has been used to diminish the high toxicity of the $\mathrm{Cr}(\mathrm{VI})$ ion in the environment. Herein, electrochemical (EC) reduction was demonstrated using Au NP-loaded Ti electrodes functionalized with 2,2':6',2"-terpyridine-4'-thiol (STpy). Cyclic voltammetry tests were performed and these revealed $\mathrm{Cr}(\mathrm{VI})$ reduction potentials around $-0.55,-0.35$, and $-0.55 \mathrm{~V}$ (vs $\mathrm{Ag} / \mathrm{AgCl}$ ) for bare $\mathrm{Ti}$, $\mathrm{Au} \mathrm{NP-loaded} \mathrm{Ti}$, and STpy-functionalized Au NP-loaded Ti (Ti-AuNP-STpy) electrodes, respectively. The reduction potential and Cr(VI) reduction performance varied with Ti oxidation state as well as surface functionalization. The EC Cr(VI) reduction using the Ti-AuNP-STpy electrode was found to have the best reduction performance. In addition, for future potential applications, the surface plasmon resonance response was also demonstrated for $\mathrm{Cr}(\mathrm{III})$ and $\mathrm{Cr}(\mathrm{VI})$ sensing over the Au-STpy surface. Thus, these novel electrode systems provide very useful information for developing improved detoxification methodologies.
\end{abstract}

Keywords: Cr(VI) reduction, Electrochemical reduction, Terpyridine-derivatized Au NPs, Cyclic voltammetry, Surface plasmon resonance

\section{Introduction}

Decontamination of hexavalent chromium $\mathrm{Cr}(\mathrm{VI})$ is a major environmental challenge [1-3]. Low limit-of-detection $\mathrm{Cr}(\mathrm{VI})$ ion sensing and safer treatments methods are actively being researched both in industry and academia [4-7]. Various safer $\mathrm{Cr}(\mathrm{VI})$ treatment methods have thus far been developed, including adsorption removal, photocatalytic reduction, and electrochemical reduction methods [8-23]. As an example of adsorption-reduction removal of $\mathrm{Cr}(\mathrm{VI})$, mesoporous polydopamine/ $/ \mathrm{TiO}_{2}$ composite nanospheres have been prepared for the adsorption of $\mathrm{Cr}(\mathrm{VI})$ ions via electrostatic interactions followed by reduction to $\mathrm{Cr}$ (III) [9]. The design of a material with suitable surface charge and electron-transfer properties is important for adsorptionreduction treatments [10-12]. Photocatalytic reduction of $\mathrm{Cr}(\mathrm{VI})$ to the less toxic $\mathrm{Cr}(\mathrm{III})$ ions using existing catalysts has been extensively been studied. The photocatalysts used include $\mathrm{TiO}_{2}$-impregnated ceramic hollow fibers [13], $\mathrm{TiO}_{2} / \mathrm{g}-\mathrm{C}_{3} \mathrm{~N}_{4}$ microspheres/reduced graphene oxide, $\mathrm{AgI} / \mathrm{TiO}_{2}$ [14], $\mathrm{Zn}$-Al-layered double hydroxide and $\mathrm{TiO}_{2}$ composites [15], $\mathrm{TiO}_{2}$-coated cellulose acetate monolithic structures [16], hollow $\mathrm{TiO}_{2}$ from polystyrene@TiO 2 [17], and $\mathrm{CoO}_{x} \mathrm{NP}$-loaded $\mathrm{TiO}_{2}$ nanosheets [18]. A key factor in this method is to design a material with a good UV-visible absorption cross section and efficient charge separation for $\mathrm{Cr}(\mathrm{VI})$ reduction [19]. Electrochemical (EC) reduction has also been an effective approach for the detoxification of $\mathrm{Cr}(\mathrm{VI})$ ions present in an acidic electrolyte. The design of a stable and efficient electrode is a major challenge. Furthermore, electrochemical behaviors (e.g., reduction-oxidation potentials) on the electrode surface are a crucial factor $[1,2]$. The redox potential is known to be highly dependent on the electrode surface. Various electrodes have been developed, these include PANI/graphene QDs on screen-printed carbon electrodes (SPCEs) [20], $\boldsymbol{\alpha}-\mathrm{Fe}_{2} \mathrm{O}_{3} / \mathrm{TiO}_{2}$ [21], $\mathrm{Au}-\mathrm{TiO}_{2}$ (rutile)/FTO [22], and $\mathrm{BiVO}_{4}$ NP-modified SPCEs [23].

Motivated by the abundant literature, to further develop the EC method and obtain new information, we demonstrated the EC reduction of $\mathrm{Cr}(\mathrm{VI})$ ions using a newly developed EC electrode consisting of terpyridine-derivatized AuNPs on Ti. It was found that the terpyridinederivatized surface played a positive role in the electrochemistry. This new methodology could be employed for improving EC reduction methods as well as other related applications.

\section{Experimental details}

The following chemicals were used as received: 2,2':6',2"-terpyridine4'-thiol (STpy, 95\%, Shanghai iChemical), potassium chromate $\left(\mathrm{K}_{2} \mathrm{CrO}_{4}\right.$, 99.0\%, Ducksan Pure Chem.), sulfuric acid $\left(\mathrm{H}_{2} \mathrm{SO}_{4}, 95-97 \%\right.$, Emsure), and dimethyl sulfoxide (DMSO, GR 99\%, Kanto Chem.). As-received Ti sheets (MSL Tools Store, China) were cleaned repeatedly by ultrasonication in acetone, isopropyl alcohol, and water and then dried under an IR lamp. The cleaned Ti sheets $(0.5 \mathrm{~cm} \times 2.0 \mathrm{~cm})$ then underwent thermal treatment at $400{ }^{\circ} \mathrm{C}$ for $2 \mathrm{~h}$ to obtain oxidized $\mathrm{Ti}$ $\left(\mathrm{TiO}_{x}\right)$ surfaces. For the preparation of AuNP-loaded Ti (Ti-AuNP) electrodes, $\mathrm{Au}(\sim 10 \mathrm{~nm})$ was sputter-coated on bare (or oxidized) $\mathrm{Ti}$ sheets using an SPT-20 ion sputter coater (COXEM Company, Korea). For the preparation of terpyridine-functionalized AuNP-loaded Ti (Ti-AuNP-STpy) electrodes, a Ti-AuNP electrode was dipped in 1 mM STpy DMSO solution for $4 \mathrm{~h}$, carefully rinsed with DMSO and 


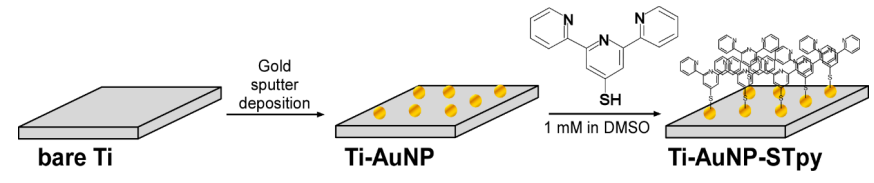

Figure 1. Terpyridine functionalization of bare or oxidized Ti sheets.

ethanol, repeatedly, and finally dried in a stream of $\mathrm{N}_{2}$ gas.

The morphologies of the electrodes were examined using fieldemission scanning electron microscopy (FE-SEM, Hitachi S-4800). The concentration of $\mathrm{Cr}(\mathrm{VI})$ ions was examined using UV-visible absorption spectrometry (SCINCO NeoSys-2000 UV-Vis spectrophotometer) before and after electrochemical testing. Top monitor changes in the chemical states of the electrodes before and after the EC experiments, X-ray photoelectron spectroscopy was carried out (Thermo Scientific K-Alpha ${ }^{+} \mathrm{X}$-ray photoelectron spectrometer, equipped with a monochromated $\mathrm{Al} \mathrm{Ka} \mathrm{X-ray} \mathrm{source} \mathrm{and} \mathrm{hemispherical} \mathrm{energy}$ analyzer). Cyclic voltammetry and EC amperometry testing was conducted using a typical three-electrode system with a counter Pt wire, a $\mathrm{Ag} / \mathrm{AgCl}$ reference, and a WPG100 Potentiostat/Galvanostat (WonATech Co., Ltd.). The electrolytes used were $1.0 \mathrm{M} \mathrm{H}_{2} \mathrm{SO}_{4}$ (aq.), 1 (and 10) $\mathrm{mM} \mathrm{Cr}(\mathrm{VI}) / 1.0 \mathrm{M} \mathrm{H}_{2} \mathrm{SO}_{4}$ (aq.), and 1 (and 10) $\mathrm{mM} \mathrm{Cr}(\mathrm{VI}) / 1.0 \mathrm{M}$ $\mathrm{H}_{2} \mathrm{SO}_{4}$ (aq.) solutions. The working electrodes tested were bare Ti, TiAuNP, Ti-AuNP-STpy, bare $\mathrm{TiO}_{x}, \mathrm{TiO}_{x}$-AuNP, and $\mathrm{TiO}_{x}$-AuNP-STpy electrodes.

\section{Results and discussion}

A key aspect of this study was the preparation of the TiAuNP-STpy electrode, which is depicted in Fig. 1, and described in the Experimental details above. In our method for the preparation of the Ti-AuNP-STpy electrode, Au NP-loaded Ti sheets are immersed in a $1 \mathrm{mM}$ STpy DMSO solution for $6 \mathrm{~h}$ and then carefully rinsed. During the immersion, Au-S covalent bond formation occurs between the Au NPs and STpy ligands [24]. This newly developed electrode system is expected to function via strong interactions between three $\mathrm{N}$ atoms in the STpy ligands and guest $\mathrm{Cr}(\mathrm{VI})$ ions.

Figure 2 shows the morphologies of bare Ti, Ti-AuNP-STpy, Ti-AuNP after Cr(VI) reduction, and Ti-AuNP-STpy after Cr(VI) reduction, all obtained via SEM. The image of the AuNP-loaded Ti sheet displays a uniform distribution of Au NPs before and after STpy functionalization. The surface morphology is clearly different before and after Au sputter deposition. For the Ti-AuNP and Ti-AuNP-STpy electrodes after EC $\mathrm{Cr}(\mathrm{VI})$ reduction, the morphology is markedly changed compared to that of the intact Ti-AuNP-STpy sample. The $\mathrm{Au} \mathrm{NP}$ aggregate, forming a large Au island. Electric-field-assisted $\mathrm{Au}$ $\mathrm{NP}$ aggregation has been reported in the literature [25]. When $\mathrm{Au}$ aggregates, it is plausible that the EC efficiency may be reduced.

Figure 3 shows cyclic voltammetry (CV) curves for bare the $\mathrm{Ti}$, Ti-AuNP, and Ti-AuNP-STpy electrodes acquired between -0.8 and $+0.2 \mathrm{~V}$ (vs. $\mathrm{Ag} / \mathrm{AgCl}$ ) at a scan rate of $100 \mathrm{mV} / \mathrm{s}$ in blank $1.0 \mathrm{M} \mathrm{H}_{2} \mathrm{SO}_{4}$, $1 \mathrm{mM} \mathrm{Cr}(\mathrm{III}) / 1.0 \mathrm{M} \mathrm{H}_{2} \mathrm{SO}_{4}$, and $1 \mathrm{mM} \mathrm{Cr}(\mathrm{VI}) / 1.0 \mathrm{M} \mathrm{H}_{2} \mathrm{SO}_{4}$ electrolyte solutions. In blank 1.0 $\mathrm{M} \mathrm{H}_{2} \mathrm{SO}_{4}$, no redox peaks are observed. Instead, a current density $(\mathrm{CD})$ increase is seen at negative potentials. For the Ti-AuNP and Ti-AuNP-STpy electrodes, the CD increases more sharply above $-0.3 \mathrm{~V}$. The sharp $\mathrm{CD}$ increase is attributed to the hydrogen evolution reaction (HER) [26,27]. For the $10 \mathrm{mM} \mathrm{Cr}(\mathrm{III}) / 1.0 \mathrm{M} \mathrm{H}_{2} \mathrm{SO}_{4}$ electrolyte, no reduction peak occurs in the negative potential region

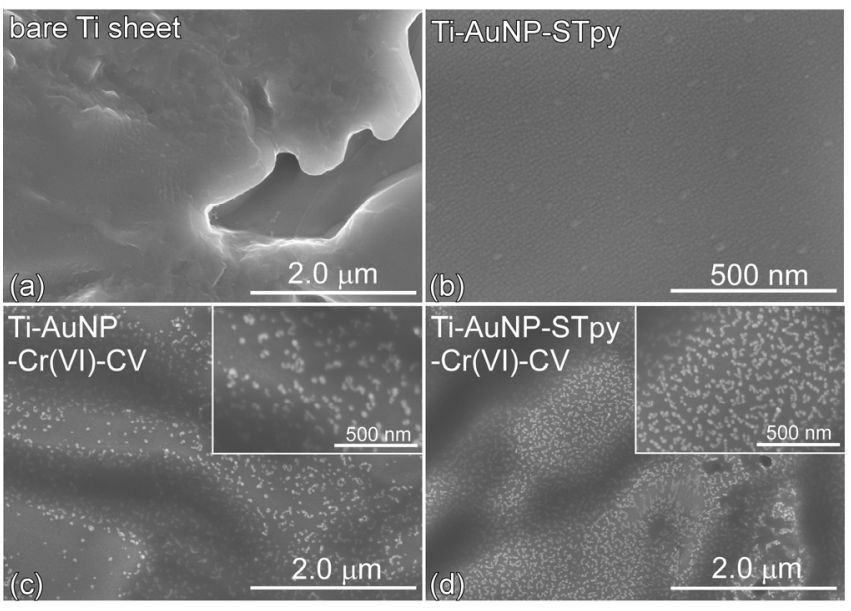

Figure 2. SEM images of (a) bare Ti and (b) Ti-AuNP-STpy electrodes before electrochemical testing, and of (c) Ti-AuNP and (d) Ti-AuNP-STpy electrodes after electrochemical testing.

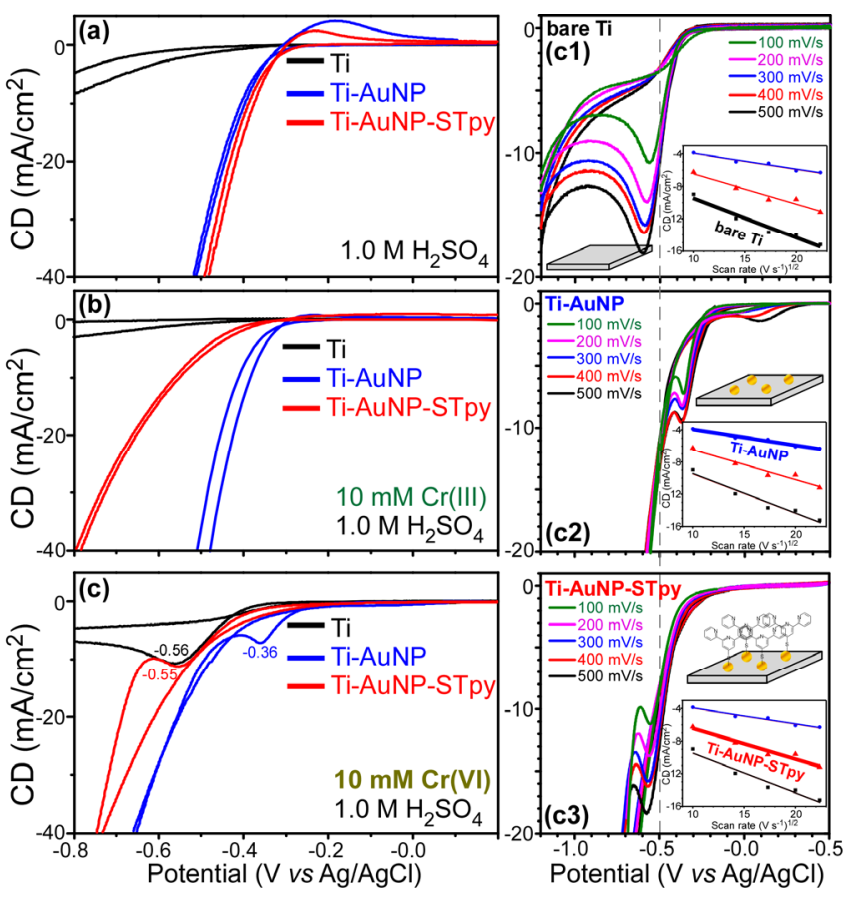

Figure 3. Cyclic voltammetry curves at $100 \mathrm{mV} / \mathrm{s}$ for bare Ti, Ti-AuNP, and TiAuNP-STpy electrodes obtained in (a) blank $1.0 \mathrm{M} \mathrm{H}_{2} \mathrm{SO}_{4}$, (b) $10 \mathrm{mM} \mathrm{Cr}$ (III)/1.0 M $\mathrm{H}_{2} \mathrm{SO}_{4}$, and (c) $10 \mathrm{mM} \mathrm{Cr}(\mathrm{VI}) / 1.0 \mathrm{M} \mathrm{H}_{2} \mathrm{SO}_{4}$. CV curves measured at various scan rates for (d) bare Ti, (e) Ti-AuNP, and (f) Ti-AuNP-STpy electrodes in $10 \mathrm{mM} \mathrm{Cr}(\mathrm{VI})$ /0.1 $\mathrm{M} \mathrm{H}_{2} \mathrm{SO}_{4}$. The insets of (c1), (c2), and (c3) are plots of $\mathrm{CD}$ (and potential) vs square root of scan rate $\left(v^{1 / 2}\right)$ for the Ti, Ti-AuNP, and Ti-AuNP-STpy electrodes.

as expected, and HER CD is also observed. In the $10 \mathrm{mM} \mathrm{Cr}(\mathrm{VI}) / 0.1$ $\mathrm{M} \mathrm{H}_{2} \mathrm{SO}_{4}$ electrolyte, peaks are generated in the $\mathrm{CV}$ curves of all three electrodes, and this is attributed to the reduction of $\mathrm{Cr}(\mathrm{VI})$ to $\mathrm{Cr}(\mathrm{III})$. $\mathrm{The} \mathrm{Cr}(\mathrm{VI})$ reduction potentials are observed at approximately -0.55 , -0.35 , and $-0.55 \mathrm{~V}$ (vs $\mathrm{Ag} / \mathrm{AgCl}$ ) for the bare $\mathrm{Ti}, \mathrm{Au} \mathrm{NP}$-loaded $\mathrm{Ti}$, and STpy functionalized Au NP-loaded Ti electrodes, respectively. A lower negative potential is demonstrated for the Ti-AuNP electrode compared to those for the other two electrodes, although the $\mathrm{CD}$ is relatively lower. The less negative (or more positive) potential for Ti- 


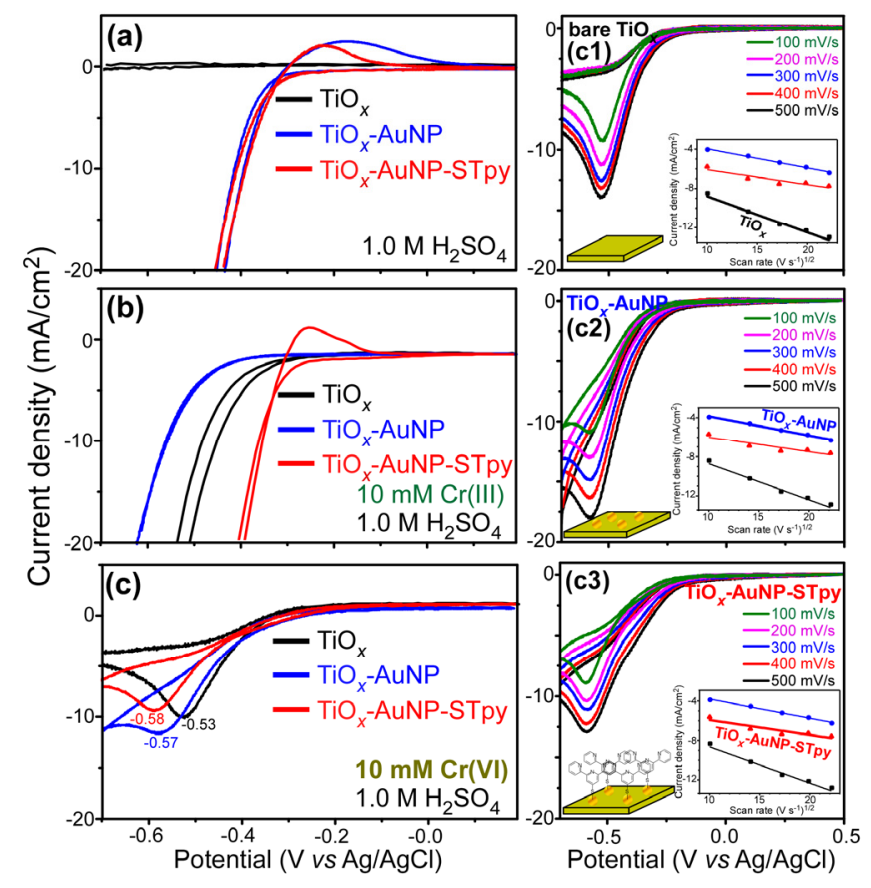

Figure 4. Cyclic voltammetry curves at $100 \mathrm{mV} / \mathrm{s}$ for bare $\mathrm{TiO}_{x}, \mathrm{TiO}_{x}$-AuNP, and $\mathrm{TiO}_{x^{-}}$ AuNP-STpy electrodes obtained in (a) blank $1.0 \mathrm{M} \mathrm{H}_{2} \mathrm{SO}_{4}$, (b) $10 \mathrm{mM} \mathrm{Cr}(\mathrm{III}) / 1.0 \mathrm{M}$ $\mathrm{H}_{2} \mathrm{SO}_{4}$, and (c) $10 \mathrm{mM} \mathrm{Cr}(\mathrm{VI}) / 1.0 \mathrm{M} \mathrm{H}_{2} \mathrm{SO}_{4}$. CV curves measured at various scan rates for (c1) bare $\mathrm{TiO}_{x},(\mathrm{c} 2) \mathrm{TiO}_{x}$-AuNP, and (c3) TiO $\mathrm{T}_{x}$-AuNP-STpy electrodes in 10 $\mathrm{mM} \mathrm{Cr}(\mathrm{VI}) / 1.0 \mathrm{M} \mathrm{H}_{2} \mathrm{SO}_{4}$. The insets of (c1), (c2), and (c3) are plots of $\mathrm{CD}$ (and potential) vs square root of scan rate $\left(v^{1 / 2}\right)$ for the $\mathrm{TiO}_{x}, \mathrm{TiO}_{x}-\mathrm{AuNP}$, and $\mathrm{TiO}_{x}$-AuNP-STpy electrodes.

AuNP could be due to the activity of the Au NPs. Similar observations have been reported in the literature [28]. In the CV curves acquired at various scan rates $-100,200,300,400$, and $500 \mathrm{mV} / \mathrm{s}$ - the reduction potential does not significantly shift toward more negative potentials as the scan rate increases. However, the corresponding $\mathrm{CD}$ levels increase with scan rate. The $\mathrm{CD}$ intensities of the electrodes at a given scan rate increase in the order Ti-AuNP $<$ Ti-AuNP-STpy $<$ bare Ti. The bare Ti electrode generates the highest $\mathrm{CD}$, but the signal is much broader than those found in the other two electrodes. The CD increase is observed to be linear with the square root of the scan rate, which is typical of a diffusion-controlled reaction process $[7,16]$.

For comparison with the Ti surface, the oxidized Ti surface was also tested. Figure 4 shows CV curves for bare the $\mathrm{TiO}_{x}, \mathrm{TiO}_{x}-\mathrm{AuNP}$, and $\mathrm{TiO}_{x}$-AuNP-STpy electrodes acquired in the range of -0.7 to +0.2 $\mathrm{V}$ (vs $\mathrm{Ag} / \mathrm{AgCl}$ ) at a scan rate of $100 \mathrm{mV} / \mathrm{s}$ in blank $0.1 \mathrm{M} \mathrm{H}_{2} \mathrm{SO}_{4}, 10$ $\mathrm{mM} \mathrm{Cr}(\mathrm{III}) / 1.0 \mathrm{M} \mathrm{H}_{2} \mathrm{SO}_{4}$, and $10 \mathrm{mM} \mathrm{Cr}(\mathrm{VI}) / 1.0 \mathrm{M} \mathrm{H}_{2} \mathrm{SO}_{4}$ electrolytes. In blank $1.0 \mathrm{M} \mathrm{H}_{2} \mathrm{SO}_{4}$ and $10 \mathrm{mM} \mathrm{Cr}(\mathrm{III}) / 1.0 \mathrm{M} \mathrm{H}_{2} \mathrm{SO}_{4}$, no redox peaks are observed, as for the Ti electrodes shown in Fig. 3. Instead, $\mathrm{CD}$ increases are observed at negative potentials. The $\mathrm{CD}$ levels of the $\mathrm{Au}$ NP-loaded electrodes are seen to sharply increase above $-0.3 \mathrm{~V}$. In $10 \mathrm{mM} \mathrm{Cr}$ (III)/1.0 $\mathrm{M} \mathrm{H}_{2} \mathrm{SO}_{4}$, the $\mathrm{CD}$ increases for the electrodes occur, starting at the lowest potential, in the order $\mathrm{TiO}_{x}-\mathrm{AuNP}<\mathrm{TiO}_{x}<$ $\mathrm{TiO}_{x}$-AuNP-STpy. The CD increase for the $\mathrm{TiO}_{x}$-AuNP-STpy electrode occurs at a much lower negative potential. In the $10 \mathrm{mM} \mathrm{Cr}(\mathrm{VI}) / 1.0 \mathrm{M}$ $\mathrm{H}_{2} \mathrm{SO}_{4}$ electrolyte, $\mathrm{Cr}(\mathrm{VI})$ reduction potentials are observed around $0.55,-0.35$, and $-0.55 \mathrm{~V}$ (vs $\mathrm{Ag} / \mathrm{AgCl}$ ) for the bare $\mathrm{TiO}_{x}, \mathrm{Au} \mathrm{NP}-$ loaded $\mathrm{TiO}_{x}$, and $\mathrm{STpy}$ functionalized $\mathrm{Au}$ NP-loaded $\mathrm{TiO}_{x}$ electrodes, respectively. The reduction potentials are shifted negatively, compared

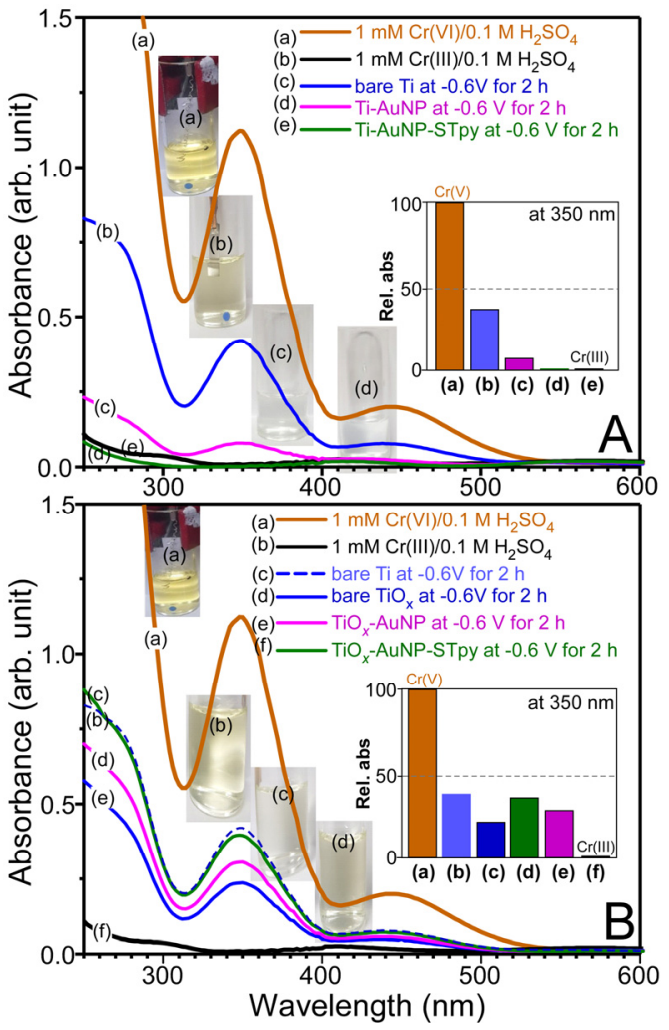

Figure 5. UV-visible absorption spectra for $\mathrm{Cr}(\mathrm{VI}) / 0.1 \mathrm{M} \mathrm{H}_{2} \mathrm{SO}_{4}$ after amperometry reduction testing for $2 \mathrm{~h}$ at $-0.6 \mathrm{~V}$ of (a) bare Ti, Ti-AuNP, and Ti-AuNP-STpy, (b) bare $\mathrm{TiO}_{x}, \mathrm{TiO}_{x}$-AuNP, and $\mathrm{TiO}_{x}$-AuNP-STpy electrodes. The UV-visible absorption spectra of $1 \mathrm{mM} \mathrm{Cr}(\mathrm{III}) / 0.1 \mathrm{M} \mathrm{H}_{2} \mathrm{SO}_{4}$ and $1 \mathrm{mM} \mathrm{Cr}(\mathrm{VI}) / 0.1 \mathrm{M} \mathrm{H}_{2} \mathrm{SO}_{4}$ are shown for reference. Insets show the decrease in peak $(350 \mathrm{~nm})$ intensity for the corresponding absorption spectra.

with $-0.55,-0.35$, and $-0.55 \mathrm{~V}$ for the bare $\mathrm{Ti}$, Ti-AuNP, and $\mathrm{Ti}-$ AuNP-STpy electrodes, respectively. The reduction peaks are also broader than those of the bare Ti, Ti-AuNP, and Ti-AuNP-STpy electrodes. This indicates that the support plays a significant role in the electrochemistry. The CV curves acquired at 100, 200, 300, 400, and $500 \mathrm{mV} / \mathrm{s}$ indicate that there is no significant change with scan rate for the reduction potential. However, the corresponding $C D$ levels are seen to increase with scan rate. At a each scan rate, the $\mathrm{CD}$ intensities of the electrodes increase in the order $\mathrm{TiO}_{x}-\mathrm{AuNP}<\mathrm{TiO}_{x^{-}}$ AuNP-STpy $<$ bare $\mathrm{TiO}_{x}$. The $\mathrm{TiO}_{x}$ electrode produces the highest $\mathrm{CD}$ and sharpest $\mathrm{CD}$ increase with scan rate. As for the Ti-supported electrodes, behavior typical of a diffusion-controlled reaction process is seen, that is, $\mathrm{CD}$ increases linearly with the square root of the scan rate $\left(v^{1 / 2}\right)[7,16]$.

The $\mathrm{Cr}(\mathrm{VI})$ reduction performances of the bare $\mathrm{Ti}$, Ti-AuNP, Ti-AuNP-STpy, bare $\mathrm{TiO}_{x}, \mathrm{TiO}_{x}$-AuNP, and $\mathrm{TiO}_{x}$-AuNP-STpy electrodes were further examined by amperometry at a potential of $-0.6 \mathrm{~V}$ in a test solution of $1 \mathrm{mM} \mathrm{Cr}(\mathrm{VI}) / 0.1 \mathrm{M} \mathrm{H}_{2} \mathrm{SO}_{4}$. The corresponding UVvisible absorption spectra are shown in Fig. 5. The UV-visible absorption spectrum of yellow $1 \mathrm{mM} \mathrm{Cr}(\mathrm{VI}) / 0.1 \mathrm{M} \mathrm{H}_{2} \mathrm{SO}_{4}$ solution includes a broad absorption peak at $350 \mathrm{~nm}$. The UV-visible absorption spectrum of $1 \mathrm{mM} \mathrm{Cr}(\mathrm{III}) / 0.1 \mathrm{M} \mathrm{H}_{2} \mathrm{SO}_{4}$ solution does not include the same absorption peak. Therefore, the absorption intensity at $350 \mathrm{~nm}$ was used for monitoring $\mathrm{Cr}(\mathrm{VI})$ reduction [19]. In the amperometry tests carried out at $-0.6 \mathrm{~V}$ for $2 \mathrm{~h}$ over the bare Ti, Ti-AuNP, and Ti-AuNP- 

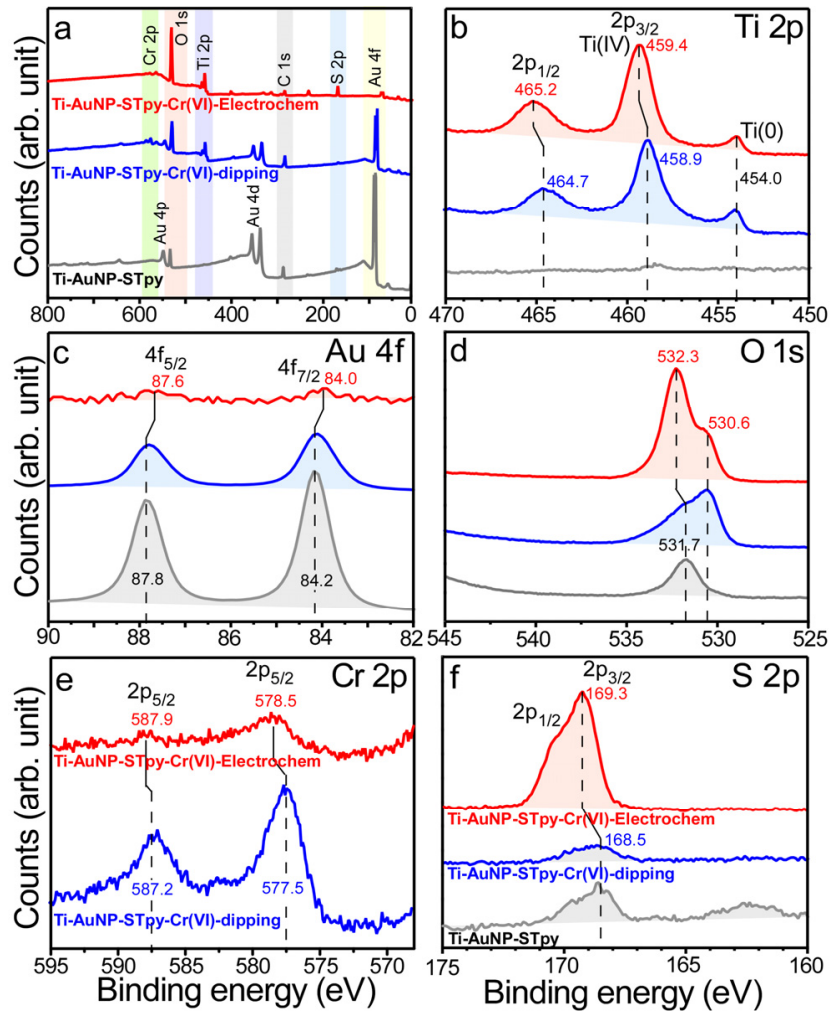

Figure 6. (a) Survey, (b) Ti 2p, (c) Au 4f, (d) $01 \mathrm{~s}$, (e) $\mathrm{Cr} 2 \mathrm{p}$, and (f) $S 2 p$ XPS spectra for as-prepared Ti-AuNP-STpy electrode, Ti-AuNP-STpy electrode immersed in the $1 \mathrm{mM} \mathrm{Cr}(\mathrm{VI})$ solution, and Ti-AuNP-STpy electrode after EC testing in the $\mathrm{Cr}(\mathrm{VI})$ solution.

STpy electrodes, 60,90 , and $100 \%$ reduction efficiencies are indicated, respectively, for the UV-visible absorption intensities. The Ti-AuNPSTpy electrode shows the best rection performance. For this electrode, the yellow color of the solution is completely lost during the test, an indication of complete $\mathrm{Cr}(\mathrm{VI})$ reduction. For the oxidized Ti supports, the $\mathrm{Cr}(\mathrm{VI})$ reduction performance is poorer. However, the unmodified oxidized electrode performs better than the bare $\mathrm{Ti}$ electrode. In amperometry tests at $-0.6 \mathrm{~V}$ for $2 \mathrm{~h}$ over bare $\mathrm{TiO}_{x}, \mathrm{TiO}_{x}$-AuNP, and $\mathrm{TiO}_{x}$-AuNP-STpy electrodes, 80,62 , and $72 \%$ reduction efficiencies, respectively, are indicated by the UV-visible absorption intensities. The modified $\mathrm{TiO}_{x}$ electrodes have lower efficiencies than the corresponding $\mathrm{Ti}$ electrodes. It is well-known that $\mathrm{Cr}(\mathrm{VI})$ ions in acidic conditions are mainly present in the form of $\mathrm{Cr}_{2} \mathrm{O}_{7}{ }^{2-}$ via $2 \mathrm{HCrO}_{4}{ }^{-} \rightleftharpoons$ $\mathrm{Cr}_{2} \mathrm{O}_{7}{ }^{2-}+\mathrm{H}_{2} \mathrm{O}$ [29]. The electrochemical reduction mechanism has been proposed to be $\mathrm{HCrO}_{4}^{-}(\mathrm{VI})+7 \mathrm{H}^{+}+3 \mathrm{e}^{-} \rightarrow \mathrm{Cr}(\mathrm{III})+4 \mathrm{H}_{2} \mathrm{O}[28,30]$.

$\mathrm{X}$-ray photoelectron spectroscopy (XPS) was carried out on the Ti-AuNP-STpy, Ti-AuNP-STpy (immersed in the $\mathrm{Cr}^{6+}$ solution), and Ti-AuNP-STpy (after the EC tests in the $\mathrm{Cr}^{6+}$ solution) electrodes and the results are displayed in Fig. 6. The survey XP spectra include peaks that are assigned to $\mathrm{Ti}$ (Ti Support), Au (overlayer), C (functionalized STpy), and S (S of STpy or sulfate ions) species, as expected. Peaks assigned to $\mathrm{Cr}$ species were detected in the spectra for the Ti-AuNPSTpy electrodes measured whilst immersed in the $\mathrm{Cr}^{6+}$ solution and after EC testing. In the Ti $2 p$ spectrum of the as-prepared Ti-AuNPSTpy electrode, the Ti $2 \mathrm{p}$ signal is weak, due to thick overlayer of $\mathrm{Au}$ and terpyridine. For the Ti-AuNP-STpy electrode in the $\mathrm{Cr}^{6+}$ solution, two strong peaks in the $\mathrm{Ti} 2 \mathrm{p}$ spectrum are observed, at 464.7 and

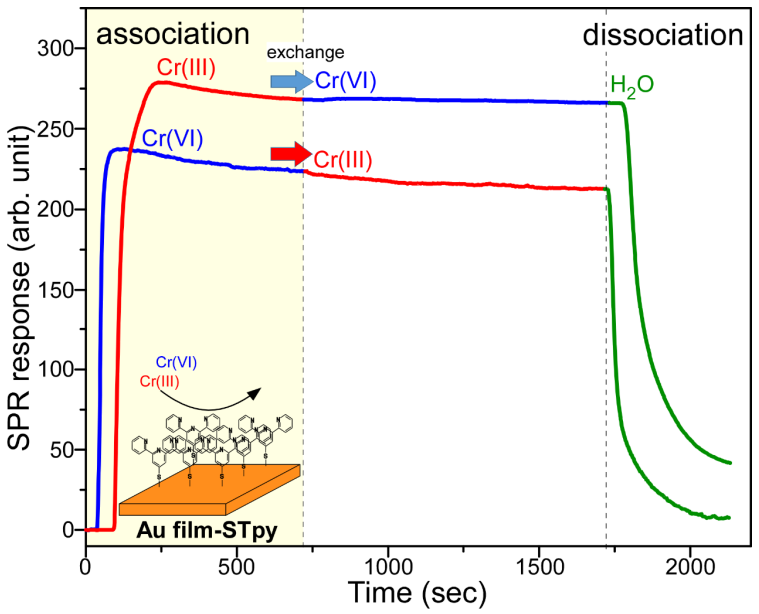

Figure 7. SPR responses of $1 \mathrm{mM} \mathrm{Cr}(\mathrm{III})$ and $\mathrm{Cr}(\mathrm{VI})$ solutions measured over AuSTpy film surface.

$458.9 \mathrm{eV}$, suggesting a spin-orbit splitting of $5.8 \mathrm{eV}$ and an assignment to Ti $2 \mathrm{p}_{1 / 2}$ and $\mathrm{Ti} 2 \mathrm{p}_{3 / 2}$ levels, respectively, of Ti(IV) species [31]. A smaller signal is observed at a binding energy (BE) of $454.0 \mathrm{eV}$, assigned to the $\mathrm{Ti} 2 \mathrm{p}_{3 / 2}$ peak of metallic $\mathrm{Ti}(0)$ [32]. The increase in the Ti $2 p$ XPS signal upon immersion of the electrode into the $\mathrm{Cr}(\mathrm{VI})$ solution is due to the fact that some Au NP aggregation occurs during the interaction between $\mathrm{Cr}(\mathrm{VI})$ and the terpyridine ligand. Three Lewis basic $\mathrm{N}$ groups of STpy are expected to strongly interact with the Lewis acidic $\mathrm{Cr}(\mathrm{VI})$ ions [7]. Therefore, the Ti support surface is exposed outwards because of Au NP aggregation. After EC testing, the Ti $2 p$ signal assigned to metallic $\operatorname{Ti}(0)$ showed no critical change, remaining at a $\mathrm{BE}$ of $454.0 \mathrm{eV}$, while the Ti $2 \mathrm{p}$ signals of the $\mathrm{Ti}(\mathrm{IV})$ species shifted to a $0.5-\mathrm{eV}$ higher BE. This indicates that surface Ti species may interact with $\mathrm{Cr}$ species during the EC. In the $\mathrm{Au} 4 \mathrm{f}$ spectrum of the as-prepared Ti-AuNP-STpy electrode, the BEs of the $\mathrm{Au} 4 \mathrm{f}_{7 / 2}$ and $4 \mathrm{f}_{5 / 2}$ electrons are observed at 84.2 and $87.8 \mathrm{eV}$, respectively, with a spin-orbit splitting of $3.6 \mathrm{eV}$. This $\mathrm{BE}$ position is attributed to the attraction between the metallic $\mathrm{Au}$ and thiol. Upon immersing the electrode in the $\mathrm{Cr}^{6+}$ solution, the $\mathrm{Au} 4 \mathrm{f}$ signal is diminished as a result of the aggregation of Au NPs during the interaction between $\mathrm{Cr}(\mathrm{VI})$ and the terpyridine ligand, as mentioned above in discussing the Ti $2 p$ XPS. After the EC test, the Au $4 \mathrm{f}$ signal is markedly diminished, which is attributed to the removal from the surface of the Au NPs during the $2 \mathrm{~h}$ reduction test. The $\mathrm{O} 1 \mathrm{~s}$ spectrum of the as-prepared Ti-AuNPSTpy electrode features the $\mathrm{O} 1 \mathrm{~s} \mathrm{BE}$ at $531.7 \mathrm{eV}$, a peak that is attributed to surface-adsorbed oxygen [31]. Upon immersing the electrode in the $\mathrm{Cr}^{6+}$ solution, the $\mathrm{O} 1 \mathrm{~s} \mathrm{BE}$ appears at $530.6 \mathrm{eV}$, and this signal is attributed to lattice oxygen of $\mathrm{Ti}(\mathrm{IV})$ oxide species. The appearance of lattice oxygen is a result of aggregation of overlayer Au NPs, as mentioned above. After the EC testing, the $\mathrm{O} 1 \mathrm{~s}$ peak at $530.6 \mathrm{eV}$ remained unchanged but the peak at $532.3 \mathrm{eV}$ was significantly enhanced, due to an increase in surface $\mathrm{OH}$ species such as Ti-OH. As a consequence, the Ti $2 p$ BE was shifted to a higher BE position after the EC tests, as mentioned above. In the Cr $2 \mathrm{p}$ XP spectrum of the Ti-AuNP-STpy electrode dipped in the $\mathrm{Cr}^{6+}$ solution, two peaks are clearly observed at BEs of 578 and $587.5 \mathrm{eV}$, attributed to $\mathrm{Cr} 2 \mathrm{p}_{3 / 2}$ and Cr $2 \mathrm{p}_{1 / 2}$ peaks, respectively, of $\mathrm{Cr}(\mathrm{III})$ [33]. These $\mathrm{Cr} 2 \mathrm{p}$ peaks of $\mathrm{Cr}(\mathrm{III})$ reflect the fact that the terpyridine ligand plays a significant role in the reduction of $\mathrm{Cr}(\mathrm{VI})$ to $\mathrm{Cr}(\mathrm{III})$. After the EC testing, the $\mathrm{Cr}$ 
$2 \mathrm{p} B$ s shifted to a higher BE position, possibly due to some interaction with sulfate residues. The corresponding S 2p signals appear at approximately $169.3 \mathrm{eV}$. The S $2 \mathrm{p}$ peak at $168.5 \mathrm{eV}$ for the other two samples is assigned to thiol in the STpy-functionalized electrodes [7].

We demonstrated surface plasmon resonance (SPR) sensing performance to briefly show that the newly developed system can be applied to sensing using SPR [6]. Figure 7 shows the SPR signal response over a STpy-functionalized Au film chip upon introducing $\mathrm{Cr}(\mathrm{VI})$ and $\mathrm{Cr}(\mathrm{III})$ ions. Interestingly, a strong SPR response was observed for both $\mathrm{Cr}(\mathrm{VI})$ and $\mathrm{Cr}(\mathrm{III})$. However, the SPR signal did not change significantly when $\mathrm{Cr}(\mathrm{VI})$ was converted to $\mathrm{Cr}(\mathrm{III})$ and vice versa. This indicates that once the $\mathrm{Cr}$ ion has strongly interacted with the terpyridine ligand, no substitutional change occurs. When water is introduced, however, the signal quickly returns to its original levels. This indicates that an adsorption-desorption equilibrium may occur when changing between $\mathrm{Cr}$ ion solutions and deionized water. This preliminary result indicates that the STpy-functionalized Au chip can be used for $\mathrm{Cr}$ ion sensing based on SPR. Further investigations should be carried out, however.

\section{Conclusions}

Toward the safer electrochemical treatment of toxic $\mathrm{Cr}(\mathrm{VI})$ in solution, bare $\mathrm{Ti}$, Ti-AuNP, Ti-AuNP-STpy, bare $\mathrm{TiO}_{x}, \mathrm{TiO}_{x}$-AuNP, and $\mathrm{TiO}_{x}$-AuNP-STpy electrodes were newly developed and tested, by $\mathrm{CV}$ and amperometry, for the electrocatalytic reduction of $\mathrm{Cr}(\mathrm{VI})$ to $\mathrm{Cr}$ (III) under an acidic conditions. The $\mathrm{Cr}(\mathrm{VI})$ reduction efficiency was observed to be enhanced for the STpy functionalized Au NPloaded Ti surfaces, compared with the those of the bare Ti and Au NPloaded $\mathrm{Ti}$. $\mathrm{Cr}(\mathrm{VI})$ reduction potentials were observed at approximately $-0.55,-0.35$, and $-0.55 \mathrm{~V}$ (vs $\mathrm{Ag} / \mathrm{AgCl}$ ) for the bare $\mathrm{Ti}, \mathrm{Ti}-\mathrm{AuNP}$, and Ti-AuNP-STpy electrodes, respectively. The reduction potentials were negatively shifted when oxidized Ti supports were used. The CD increased linearly with the square root of the scan rate $\left(v^{1 / 2}\right)$, an indication of a diffusion-controlled reaction process. $\mathrm{The} \mathrm{Cr}(\mathrm{VI})$ reduction performances of the electrodes, measured by amperometry at $-0.6 \mathrm{~V}$, were found to increase in the order bare $\mathrm{Ti}<\mathrm{Ti}-\mathrm{AuNP}<\mathrm{Ti}-$ AuNP-STpy. The Ti-AuNP-STpy electrode showed 100\% reduction efficiency. The electrodes based on the oxidized Ti support were demonstrated to possess poorer efficiencies, compared to the corresponding $\mathrm{Ti}$ supports. XPS data confirmed that the Ti electrode consisted of $\mathrm{Ti}(0)$ covered by $\mathrm{Ti}(\mathrm{IV})$ oxide states. Functionalized $\mathrm{Au}$ NPs were found to be partially removed from the surface. In addition, the SPR demonstration tests for $\mathrm{Cr}(\mathrm{VI})$ and $\mathrm{Cr}(\mathrm{III})$ highlighted the potential applicability of the Au-STpy electrode system in Cr sensing. Thus, we can conclude that these test results for the newly developed electrode systems demonstrate a new methodology for the development of electrochemical $\mathrm{Cr}(\mathrm{VI})$ treatment.

\section{Acknowledgements}

This research was supported by Research Scholarship of Chungnam National University.

\section{References}

[1] Y. Zhao, D. Kang, Z. Chen, J. Zhan, and X. Wu, Int. J. Electrochem. Sci. 13, 1250 (2018).

[2] H. Peng, Y. Leng, and J. Guo, Appl. Sci. 9, 1156 (2019).
[3] W. Jin, H. Du, S. Zheng, and Y. Zhang, Electrochim. Acta 191, 1044 (2016).

[4] Y. Ma, Y. Chen, J. Liu, Y. Han, S. Ma, and X. Chen, Talanta 185, 249 (2018).

[5] W. Wang, H. Bai, H. Li, Q. Lv, Z. Wang, and Q. Zhang, J. Electroanal. Chem. 794, 148 (2017).

[6] T. T. Dung and M. Kim, Appl. Sci. Convergence Technol. 27, 184 (2018).

[7] J. M. Yi, T. J. Kim, S. J. Park, S. M. Hong, J. G. Kang, C. K. Rhee, J. Kim, and Y. Sohn, Chem. Eng. J. 402, 126266 (2020).

[8] H. S. Kim, Appl. Sci. Convergence Technol. 28, 122 (2019).

[9] P. Li, T. Fu, X. Gao, W. Zhu, C. Han, N. Liu, S. He, Y. Luo, and W. Ma, J. Chem. Eng. Data 64, 2686 (2019).

[10] J. Ding, Y. Wang, B. Wu, A. Yu, X. Zhang, B. Pan, Q. Zhang, and G. Gao, Environ. Sci. Technol. 52, 12602 (2018).

[11] Y. Hu, X. Peng, Z. Ai, F. Jia, and L. Zhang, Environ. Sci. Technol. 53,8333 (2019).

[12] S. Bae, Y. Sihn, D. Kyung, S. Yoon, T. Eom, U. Kaplan, H. Kim, T. Schafer, S. Han, and W. Lee, Environ. Sci. Technol. 52, 10647 (2018).

[13] I. G. F. Costa, N. M. Terra, V. L. Cardoso, F. R. X. Batista, and M. H. M. Reis, J. Hazard. Mater. 379, 120837 (2019).

[14] Q. Wang, X. Shi, J. Xu, J. C. Crittenden, E. Liu, Y. Zhang, and Y. Cong, J. Hazard. Mater. 307, 213 (2016).

[15] Y. Yang, L. Yan, J. Li, J. Y. Li, Tao Yan, M. Sun, and Z. Pei, Appl. Surf. Sci. 492, 487 (2019).

[16] B. A. Marinho, R. O. Cristóvão, R. Djellabi, J. M. Loureiro, R. A. R. Boaventura, and V. J. P. Vilar, Appl. Catal. B 203, 18 (2017).

[17] J. Cai, X. Wu, F. Zheng, S. Li, Y. Wu, Y. Lin, L. Lin, B. Liu, Q. Chen, and L. Lin, J. Colloid. Interface. Sci. 490, 37 (2017).

[18] D. Lu, W. Chai, M. Yang, P. Fang, W. Wu, B. Zhao, R. Xiong, and H. Wang, Appl. Catal. B 190, 44 (2016).

[19] A. K. Nayak, S. Lee, Y. I. Choi, H. J. Yoon, Y. Sohn, and D. Pradhan, ACS Sustain. Chem. Eng. 5, 2741 (2017).

[20] E. Punrat, C. Maksuk, S. Chuanuwatanakul, W. Wonsawat, and O. Chailapakul, Talanta 150, 198 (2016).

[21] P. Wang, F. Dong, M. Liu, H. He, T. Huo, L. Zhou, and W. Zhang, Environ. Sci. Pollut. Res. Int. 25, 22455 (2018).

[22] R. S. Moakhar, G. K. L. Goh, A. Dolati, and M. Ghorbani, Appl. Catal. B 201, 411 (2017).

[23] D. P. Jaihindh, B. Thirumalraj, S. M. Chen, P. Balasubramanian, and Y. P. Fu, J. Hazard. Mater. 367, 647 (2019).

[24] Y. Sohn, and J. M. White, J. Phys. Chem. C 112, 5006 (2008).

[25] Y. Sohn, D. Pradhan, J. S. Kang, and K. T. Leung, RSC Adv. 5, 31472 (2015).

[26] S. Hong, C. K. Rhee, and Y. Sohn, Catalysts 9, 494 (2019).

[27] J. Lee, S. K. Kim, and Y. Sohn, J. Ind. Eng. Chem. 62, 362 (2018).

[28] J. Tu, Y. Gan, T. Liang, H. Wan, and P. Wang, Sens. Actuators, B 272, 582 (2018).

[29] R. T. Kachoosangi and R. G. Compton, Sens. Actuators, B 178, 555 (2013).

[30] G. Bhanjana, P. Rana, G. R. Chaudhary, N. Dilbaghi, K. H. Kim, and S. Kumar, Sci. Rep. 9, 8050 (2019).

[31] J. G. Kang and Y. Sohn, J. Mater. Sci. 47, 824 (2012).

[32] A. V. Naumkin, A. Kraut-Vass, S. W. Gaarenstroom, and C. J. Powell, NIST Standard Reference Database 20, Version 4.1 (2012). https://srdata.nist.gov/xps/

[33] J. Jing, Z. Chen, Y. Bu, M. Sun, W. Zheng, and W. Li, Electrochim. Acta 304, 386 (2019). 